\title{
Preferences for variation in forest characteristics: does diversity between stands matter?
}

\section{Anna Filyushkina, Fitalew Agimass Taye, Thomas Lundhede, Niels \\ Strange \& Jette Bredahl Jacobsen}

\section{Published in Ecological Economics, 2017}

\begin{abstract}
The majority of existing studies of recreational preferences and forest characteristics focused on single stand attributes and demonstrated that people prefer stands with visual variation. However, it may be too simple since most people experience more than one stand when visiting a forest. This study aims at evaluating the effects of variation both within and between stands on recreational values. A choice experiment (CE) was applied to elicit people's preferences for forest types on their next recreational visit. Each alternative is presented with drawings of three forest stands which differ with respect to tree species, height (age) and distance to the site, the latter representing the cost factor - willingness-to-travel. Respondents also compose their ideal recreational forest by selecting three types of stands from the catalogue of drawings. We find that mixed tree species are preferred compared to monocultures. Stands with trees of varying height (uneven-aged stands) are preferred over stands consisting of trees of the same height (even-aged ones). Variation between stands is found to contribute positively to recreational value, and in some instances, this may outweigh contribution of variation within a stand. Comparing respondents' composition of their ideal forest with elicited preferences from the CE, confirm these findings.
\end{abstract}


Keywords: outdoor recreation, choice experiment, variation, forest structure, forest management, visual diversity 


\section{Introduction}

Recreation is one of the most important services forests provide to society (Daniel et al., 2012; Pearce, 2001; Slee, 2005). Forest management plays an important role in designing forests and thus affects the potential recreational attraction of the site. Hence, understanding visitor preferences for different forest characteristics or attributes and their recreational values becomes imperative in order to integrate recreational interests in policy as well as in practical decision-making.

A considerable body of literature in the field of preference research has provided insight into impacts of forest management on recreational values of forests (e.g. Schroeder \& Daniel 1981; Zube et al. 1982; Brown \& Daniel 1986; Jensen 1999a; Bliss 2000; Holgén et al. 2000; Silvennoinen et al. 2001; Heyman et al. 2011; Nielsen et al. 2012). Variation in forest and/or landscape characteristics may affect the recreational experience and thus the recreational value (Bell et al., 2005; Kaplan and Kaplan, 1989; Lee, 2001; Ode and Miller, 2011; Ribe, 1989). A number of studies have demonstrated preferences for visual diversity at a single stand level, e.g. that mixed stands in general are preferred over monocultures (see e.g. Willis et al. 2003; Nielsen et al. 2007b; Gundersen \& Frivold 2008; Dhakal et al. 2012). However, a recreational experience in a forest most often involves visits to several stands and so far, it remains unanswered whether these findings can be extrapolated to forest level i.e. how the recreational experience is affected by diversity between multiple stands. Is it merely a simple sum of the recreational experiences and values of individual stand values or a more complex judgement? The need to examine the effect of variation between stands has been expressed numerously (e.g. Ribe 1989; Mattsson \& Li 1994; Nielsen et al. 2007b; Gundersen \& Frivold 2008). However, previous examples have mostly concentrated on preference comparisons without looking at the importance of this aspect relative to 
other preferences for structures (e.g. Axelsson-Lindgren \& Sorte 1987; Price 2007; Edwards et al. 2012a).

The aim of this study is to evaluate the effect of variation within a stand and between stands on recreational preferences for forests in Denmark. Using a choice experiment (CE), respondents were asked to choose between sites for their next forest recreation visit from two alternatives - each made up by three drawings of forest stands that are characterized by tree species and height (as a function of age). Distance to the forest site was included as an attribute in order to estimate willingness to travel to the preferred forest. In addition, we asked respondents to create their ideal forest to visit by selecting drawings of three stands from a matrix of drawings, where each drawing could be chosen more than once. This was used as an internal consistency test for the

CE findings. Finally, we calculated aggregated willingness to travel (AWTT) for a number of forests (composed of three stands) for a sample mean WTT and using individual posterior estimates.

The remainder of this paper is organized as follows. Section 2 summarizes relevant literature on forest recreation and provides hypotheses for this study. Section 3 outlines the CE setting and data collection. Section 4 presents main findings and section 5 provides a discussion of their implications for forest management.

\section{Literature review and hypotheses}

A number of studies shows that visual diversity or variation within a stand of a forest is an important determinant of recreational value of forests (e.g. Ribe 1989; Lee 2001; Gustavsson et al. 2005; Nielsen et al. 2007a; Dhakal et al. 2012). Variation has also been identified as a key cognitive factor that accounts for a considerable part of expressed preferences (Kaplan \& Kaplan 1989; Nielsen \& Jensen 2007; Bell 2009; 
Ode \& Miller 2011). The present study defines forest and stand variation as presence of different levels of one or several forest characteristics (be it spatial, biological or structural) that results in a visually diverse recreational experience. In the landscape perception literature this is sometimes referred to as "complexity" (i.e. abundance of variety, where structure is not simple), "richness", "diversity", or "contrast" (e.g. Kaplan \& Kaplan 1989; Ode \& Fry 2002; Bell 2009). Hence, the visual variation depends on several features, among others tree species, tree size, stand density, presence or extent of understorey etc. This study focuses on two of them - tree species and tree height $(\mathrm{age})^{1}$. The latter acting as a proxy for forest management system; i.e. stands consisting of trees of the same height (even-aged stands) often represent a clear-cut system, whereas stands comprised of trees of varying height (uneven-aged stands) indicate practice of single-tree selection systems. Variation may appear at different spatial scales; stand, forest, and landscape level. This study addresses it from both perspectives: within a stand and between stands.

\subsection{Preferences and variation within a stand}

Studies on recreational preferences show that the most important forest structure is related to tree age - older trees are preferred over younger ones (e.g. Ribe 1989; Lindhagen \& Hörnsten 2000; Tahvanainen \& Tyrväinen 2001; Gundersen \& Frivold 2008; Edwards et al. 2012b). According to the Danish study by Koch and Jensen (1988), this effect is more prominent in broadleaved than coniferous forests. A relatively low recreational value of young stands may partially be explained by a high density of trees inside the stand, which offers low possibility for visual and physical penetration of the stand. In contrast, semi-open forests provide a better view and

\footnotetext{
${ }^{1}$ This study is focusing on "tree height" as it is a direct visual component (as opposed to age). However, the literature mainly refers to "tree age". Thus throughout this paper we use the terms height when referring to our study, but it may be interpreted as interchangeable with age.
} 
sense of safety than dense forests (Heyman, 2012; Kaplan and Kaplan, 1989) and may also be seen as more penetrable, for e.g. mushroom picking (Varela et al., 2015). However, there seems to be a large degree of heterogeneity in preferences. For instance, children and young people often favour more dense alternatives, and higher environmental knowledge often correlates with preference for more natural-looking sites (Gundersen and Frivold, 2008; Ribe, 1989; Tyrväinen et al., 2003).

Variation in tree size and tree spacing in the stand has been identified to have a positive relationship with recreational values across Europe (Edwards et al., 2012a; Willis et al., 2003). Trees of varying height are preferred over even-aged scenarios in Denmark (Nielsen et al., 2007) and a study performed in Germany demonstrated an even higher importance of structural variation under winter conditions (Elsasser et al., 2010).

Public preferences for tree species may partly be attributed to cultural and regional contextual issues. In the present paper, Denmark is used as a case where in general broadleaved and mixed forests are preferred to conifers (Jensen, 1999a; Nielsen et al., 2007; Termansen et al., 2013). It has been shown that monocultures appear to be less preferred due their limited variation (Abildtrup et al., 2013; Dhakal et al., 2012; Elsasser et al., 2010; Gundersen and Frivold, 2008; Ribe, 1989; Willis et al., 2003). However, the highest preference have been found for monocultures when they are of old age (Jensen, 1999b).

\subsection{Preferences and variation between stands}

In most cases, a recreational experience in a forest would imply that people are moving around in the forest and thus passing multiple stands. While uneven-aged mixed forest is found to provide the highest variation at a stand level, the visitor may perceive less variation if all stands in the forest are similar. This suggest forests comprised of 
uneven-aged mixed stands may have a lower recreational value, than forests with more inter-stand variation (Lindgren, 1995). Findings of Mattsson \& Li (1994) suggest that variation between stands of different ages (though each of them individually more or less uniform) is consistent with a higher non-market value. Moreover, openings in the forest provide space and visual access to more distant areas (Heyman, 2012; Kaplan and Kaplan, 1989).

Existing studies focusing on the effect of variation between stands are limited and mostly confined to pairwise comparisons. Axelsson-Lindgren \& Sorte (1987) compare in a Swedish study two trails with different extent of variation and conclude that the trail including many visually different stands had higher attractiveness among participants than the trail with lower visual diversity. Price (2007) found a similar result and stipulates that such results could be due to poor representation of visual progression through the forest. In the 1970s a sample of residents in the Oslo area reported that they preferred taking a walk in "a mixture of old and young forest" compared to taking a walk in "old forest" (Haakenstad (1972) cf Gundersen \& Frivold 2008). In a study by Koch \& Jensen (1988) Danes showed preference for forest areas that contained both broadleaved and coniferous stands, especially if the majority of stands were broadleaved. Findings of a recent expert-elicitation study (Edwards et al. 2012) on recreational values of forests demonstrate positive or a bell-shaped relationship between recreational value and "variation between stands along the path" (for Europe in general and Nordic countries respectively). Finally, results of a recent choice experiment study performed in Poland suggest that the average respondent prefers to visit forests that are comprised of stands that vary in tree species composition and age structures (Giergiczny et al., 2015). So while a few studies indicate importance of variation between stands, no studies have evaluated it relative to the variation within stands. 


\subsection{Hypotheses of this study}

The main hypothesis of the present study is that variation matters. Not only variation within stands but also variation between stands affects the recreational value of a forest. Specifically: (1) Diversity in tree species composition across stands has a positive effect on recreational value; and (2) diversity in tree height across stands has a positive effect on recreational value. In addition, we expect preferences for tree species composition and height structures within the stand to follow same pattern, i.e. (3) mixed stands are preferred to coniferous and broadleaved stands and (4) stands with trees of varying height (uneven-aged stands) are preferred to stands with trees of same height (even-aged stands). The hypotheses are tested in two ways: by eliciting peoples' preference in a CE, and by asking respondents to create their ideal forest.

\section{Method}

Discrete choice modelling is one of the main techniques used to estimate non-market values of environmental (ecosystem) services, including recreation (e.g. Adamowicz et al. 1998; Hanley et al. 1998; Scarpa et al. 2000; Hanley et al. 2002; Carlsson et al. 2003). The method was initially developed for market analysis (Louviere et al., 2000). Its formulation is based on Lancaster's demand theory (Lancaster, 1966) and McFadden's Random Utility Maximization (RUM) framework (McFadden, 1973). We use a standard random parameter logit model with panel specification, whereby we allow for preference heterogeneity, see e.g. Train (1998) for details. Thereby we are able to estimate a utility parameter, $\beta$, for each attribute entering the estimation.

The marginal rate of substitution between two attributes results in a marginal willingness to pay (WTP) when the denominator is a price. In this study, distance to be travelled is used instead of price and consequently willingness to travel (WTT) is being estimated using the following formula: 
$W T T=\frac{-\beta_{\text {attribute }}}{\beta_{\text {distance }}}$

Note: it is possible to convert this to a WTP measure using a fixed cost per kilometer travelled(see e.g. Bakhtiari et al. (2014) for an example).

\subsection{Design of the choice experiment}

In choice experiment respondents were asked to choose between two forests for their next recreational visit (example of a choice card is presented in Figure 1). Each of the two alternatives were represented by drawings ${ }^{2}$ of a forest, each forest comprising three stands and the distance that one would have to travel to reach the forest. Presence of more than one stand in each alternative and their horizontal alignment was an attempt to reflect the experience of a recreational visit to a forest (visiting several stands) and not just a single stand. The drawings included a red pictogram to the right of each stand representing an adult person visiting the forest, enabling respondents to make a judgement on the scale and height of trees. Furthermore, each stand had a label containing information on tree species and their height. All of this was explained to respondents in the text accompanying the drawings. Finally, each choice card contained a possibility of opting out by choosing the "I would not visit either of these forests" alternative.

\footnotetext{
${ }^{2}$ The drawings of each tree are provided by Dr. Anders Busse Nielsen and are modified versions of those used in Nielsen et al. (2007b)
} 
Which of these two forests you would prefer for your next visit?

If you would not visit either of them, please choose "I would not visit either of these forests".

- Please pay attention to both how forest looks and how far it is from your point of departure

- Imagine that these two are your options for the next recreational visit to the forest, regardless of what your real options are

- Please take into account that you may want to do something different than visiting a forest, e.g. if you find forest A \& B not fulfilling your expectation of a forest visit or if both of them are too far away.
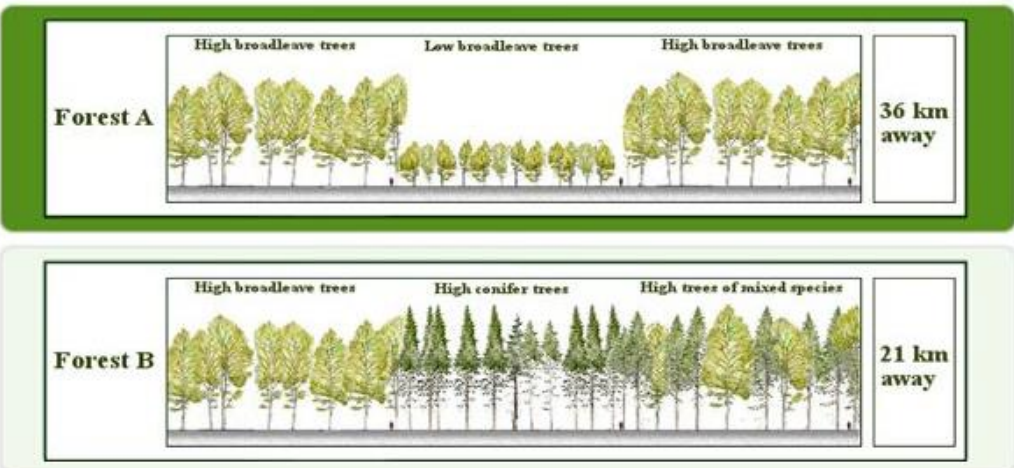

I would not visit either of these forests

Next

Figure 1: An example of a choice card. Text was in Danish, but here translated into English

A full list of the attributes and attribute levels is shown in Table 1. Tree species and height reflected the extent of variation within a stand; from coniferous or broadleaved monocultures to mixed stands and from trees of the same height within a stand (newly established, low, and high trees) to trees of varying height. Coniferous stands are represented by Norway spruce, which is the most common coniferous species in Denmark. Similarly broadleaved stands are represented by beech, which is the most common broadleaved species. Mixed stands contain a mix of beech and Norway spruce in equal proportions. For each alternative two additional attributes were derived: tree species diversity and height diversity between stands. Distance to the forest site represents the cost factor, its levels were selected based on findings from other studies of stated travel distances (e.g. Jensen 2003; Bakhtiari et al. 2014). 
Table 1: Attributes and levels with descriptions

\begin{tabular}{|c|c|c|}
\hline Attributes & Levels & Description \\
\hline Tree species & Each can take & Number of stands of each type in the three \\
\hline 1. Conifers* & $0,1,2,3$ & stands (forest). \\
\hline 2. Broadleaves & & Sum of all tree species for the entire forest is \\
\hline 3. Mixed & & 3. \\
\hline Stand height & Each can take & Number of stands of each height structure in \\
\hline 4. Newly established ${ }^{*}$ & $0,1,2,3$ & the three stands (forest). \\
\hline 5. Low trees & & Sum of all height classes for entire forest is 3 . \\
\hline 6. High trees & & \\
\hline $\begin{array}{l}\text { 7. Trees of varying } \\
\text { height }\end{array}$ & & \\
\hline $\begin{array}{l}\text { 8. Tree species } \\
\text { diversity across } \\
\text { (between) stands }\end{array}$ & $0,1,2$ & $\begin{array}{l}\text { A derived attribute } \\
0=\text { if all three stands have the same tree } \\
\text { species composition } \\
1=\text { if two out of three stands have the same } \\
\text { tree species composition } \\
2=\text { if all three stands have different tree } \\
\text { species composition }\end{array}$ \\
\hline $\begin{array}{l}\text { 9. Tree height } \\
\text { diversity across } \\
\text { (between) stands }\end{array}$ & $0,1,2$ & $\begin{array}{l}\text { Derived attribute } \\
0=\text { if all three stands have the same height } \\
\text { structure } \\
1=\text { if two out of three stands have the same } \\
\text { height structure } \\
2=\text { if all three stands have different height } \\
\text { structure }\end{array}$ \\
\hline $\begin{array}{l}\text { 10. Distance to the } \\
\text { forest }\end{array}$ & $\begin{array}{l}1,3,6,10,15,21 \\
28,36\end{array}$ & Travel distance $(\mathrm{km})$ \\
\hline
\end{tabular}


The statistical design is based on three stands each of which could be one of three species, four height levels, and then eight travel distances. We used the software Ngene to create choice cards by optimizing D-efficiency for a multinomial model with main effects and priors estimated based on the pilot sample. The design consisted of 24 choice situations distributed with an ex-ante D-error of 0.188306 . To test the specific effect of variation between stands, we constructed two derived attributes (tree species diversity and tree height diversity across stands) which were determined from the levels present in the three stands. As these are created by a combination of the others, they are in fact an aggregate of interactions and therefore not included in the D-efficient optimization in Ngene. To ensure balanced representation of levels of the two derived attributes, eight extra choice sets were constructed manually maintaining balance of other attributes' levels. Furthermore, attribute levels for 12 dominant alternatives were changed manually ${ }^{3}$. Based on the literature review presented above, a dominant alternative in this case is an alternative at short distance with preferred tree species types and height structures based on learnings form previous studies (e.g. forest stands consisting of mixed or broadleaved tree species and trees of high or varying height). The final design thus contained 32 choice cards distributed to four blocks, so that each respondent was presented with eight consecutive choice sets. Evaluation of the final design resulted in D-error of 0.151243 . The order of the choice sets in each block was randomized between respondents.

\footnotetext{
${ }^{3}$ Instead of doing this manually restrictions could have been included to the Ngene code. However, it is our experience that restrictions sometimes cause the optimization process in Ngene to be problematic, and testing the effect of the manual swopping in terms of balance and d-error provides a more efficient design
} 
As the design included the derived attributes, we wanted to test whether the design would bias results or not. To do so, we simulated 1000 answers to all choice sets based on a set of a priori set beta parameters. Following, we estimated a model based on these simulated answers. We were able to obtain parameters in the estimation for a variety of a priori set beta parameters and errors.

\subsection{Data and sampling}

The choice experimental data was collected in Denmark using a structured internetbased questionnaire. Two focus group interviews, individual interviews and an online pilot survey involving a total of 133 respondents were carried out in order to test the survey instrument, evaluate attribute levels and adjust both. The main survey was administered online from May $19^{\text {th }}$ to June $8^{\text {th }} 2015$ and was managed by a survey company. The company invited members of their online panel to participate in the survey, ensuring representativeness of the sample. A total of 3,665 individuals accepted the invitation of which 1,339 respondents were screened out and excluded in the survey procedures to maintain representativeness in terms of gender, age, location and income of the respondent. From the remaining 2,326 respondents, a total of 1,226 respondents completed the questionnaire, which equals a response rate of $53 \%$.

\subsection{Content of the questionnaire}

The questionnaire contained five sections. The first section assessed respondents' recreational behaviour including frequency of visits to the forests, type of activities, transportation mode and details of their last forest visit. This also served as a means to let them consider actively their behaviour before expressing their preferences. This was followed by a section assessing respondents' knowledge about common tree species. Half of the respondents received a small quiz asking them to identify and name 
common tree species from drawings and categorize them into native and non-native. The other half were simply given information about common tree species growing in Denmark. We found no significant difference between the two splits in respect to scale factor of evaluating levels of attributes, hence, we used a pooled sample for analysis. Sections three and four were aiming at capturing preferences for different forests using two methods: a choice experiment followed by a series of debriefing questions and an additional exercise where respondents composed their ideal forest for recreation respectively. In this additional exercise respondents were selecting three stands from a matrix of all drawings applied in the choice cards. The final forest could potentially consist of three similar stands, i.e. each stand could be chosen several times. The fifth section contained questions about their socio-demographic background.

\section{Results}

The socio-demographic characteristics of the samples were compared with the Danish population from Statistics Denmark ${ }^{4}$. We fail to reject the null hypothesis (at the $5 \%$ level) of equal samples for age and region, but not for gender, income, education and employment status (see Table A in Supplementary materials). The sample contains more women than in the national population, and more respondents in the lower income categories. Our sample has more respondents that have university degree but less in primary education; and more retired people but less that are in education.

Most of the respondents ( $83 \%$ ) stated that they had recreational forest visits within the last year. The average frequency of visits is 28 times a year with a median of four times a year ${ }^{5}$. More than $50 \%$ of the respondents indicated that they visited forests within the

\footnotetext{
${ }^{4}$ www.statistikbanken.dk

${ }^{5}$ The sample contains respondents who reported visiting a forest more than 1000 times a year - probably they live close to forest in which they can walk several times a day.
} 
last two weeks (of filling out the questionnaire). Most respondents stay in the forest for 30-120 minutes. About $40 \%$ of the respondents use their personal car to reach the forest while $13 \%$ use bicycle and about $39 \%$ travel on foot. As for the mode of transportation that respondents considered while making decisions in the choice experiment, a total of $61 \%$ indicated that they made choices assuming the same mode of transport as in their last forest visit. The share of respondents considering traveling by car remains almost the same (45\%). However, the share of respondents considering to walk to the forest is only $21 \%$, and those considering to bike is $21 \%$. This might be the result of longer distances presented in the choice cards. We calculated the actual travel distance in their most recent recreational visit to a forest ${ }^{6}$. The mean travel distance is $4.2 \mathrm{~km}$ for walkers, $6.8 \mathrm{~km}$ for cyclists, and $14.5 \mathrm{~km}$ or those who used a personal car. In the choice modelling, we assume that potential shift in transport mode does not change the functional form for the distance parameters.

The RPL specification used in this study assumes stable preferences for an individual across all choice cards (Train, 2003). Estimation was performed with 1,000 Halton draws in NLOGIT 5.0 software (Greene, 2012a). Between individuals, all the coefficients are assumed to be randomly and independently normally distributed except for the coefficient of distance, which is assumed to be fixed ${ }^{7}$. Tree species and height are dummy coded, whereas diversity indices and distance are coded linearly. A forest consisting of three coniferous stands is the reference for tree species, and thus variables 'Broadleaves' and 'Mixed' count the number of stands with broadleaves or

\footnotetext{
${ }^{6}$ In the first section of the questionnaire we asked respondents to point to location of their last forest visit and place of departure on a google map provided in the online interface.

${ }^{7}$ A lognormal distribution of distance may be more appropriate, so we tested this and it did not cause any important change in the results. For ease of calculating WTT estimates, we therefore chose to keep it fixed.
} 
mixed respectively instead (i.e. 0 to 3 ). For stand height, a forest consisting of 3 newly established stands is taken as the reference level, and the other variables like 'Low trees' are counting the number of stands in the forest from 0-3 with low trees. The constant of the regression, the ASC, is coded as dummy (= 1 for alternatives 1 and 2 and 0 for the "not visiting either of the presented forests" alternative).

Table 2 shows the parameter estimates and model performance characteristics. The adjusted McFadden's $R^{2}$ of the final estimation is 0.23 , which is considered as a good fit (Louviere et al., 2000). All estimated parameters are significant, and with exception of distance have a positive effect on attractiveness of forest sites for recreation. As expected, the coefficient for distance to a forest is negative. ASC represents a negative utility of visiting a forest comprised entirely of newly established coniferous stands at a distance of zero (with tree species diversity and height diversity across stands being zero). 
Table 2: Output from Random parametric logit estimation

\begin{tabular}{|c|c|c|c|c|}
\hline Attributes & Coefficient & Standard error & Z & Prob $|z|>Z^{*}$ \\
\hline Broadleaves $^{a}$ & $0.37^{\star \star *}$ & 0.03 & 13.39 & .0000 \\
\hline Mixed $^{a}$ & $0.51^{* * *}$ & 0.03 & 16.49 & .0000 \\
\hline Low trees ${ }^{\mathrm{b}}$ & $1.07^{* * *}$ & 0.04 & 28.16 & .0000 \\
\hline High trees ${ }^{\mathrm{b}}$ & $1.22^{* * *}$ & 0.04 & 28.89 & .0000 \\
\hline Trees of varying height $^{\mathrm{b}}$ & $1.48^{* * *}$ & 0.05 & 30.29 & .0000 \\
\hline $\begin{array}{l}\text { Tree species diversity } \\
\text { across stands }\end{array}$ & $0.23^{\star \star *}$ & 0.03 & 7.51 & .0000 \\
\hline $\begin{array}{l}\text { Tree height diversity } \\
\text { across stands }\end{array}$ & $0.24^{* * *}$ & 0.03 & 7.77 & .0000 \\
\hline Distance & $-0.10^{\star \star \star}$ & 0.00 & -32.22 & .0000 \\
\hline ASC & $-1.35^{\star * *}$ & 0.14 & -9.69 & .0000 \\
\hline \multicolumn{5}{|l|}{ Standard deviations } \\
\hline Broadleaves & $0.51^{* * *}$ & 0.03 & 15.40 & .0000 \\
\hline Mixed & $0.29^{* * *}$ & 0.05 & 5.62 & .0000 \\
\hline Low trees & 0.01 & 0.08 & 0.15 & .8817 \\
\hline High trees & $0.56^{* * *}$ & 0.04 & 12.57 & .0000 \\
\hline Trees of varying height & $0.31^{* * *}$ & 0.07 & 4.19 & .0004 \\
\hline $\begin{array}{l}\text { Tree species diversity } \\
\text { across stands }\end{array}$ & $0.27^{\star \star \star}$ & 0.08 & 3.50 & .0000 \\
\hline $\begin{array}{l}\text { Tree height diversity } \\
\text { across stands }\end{array}$ & $0.40^{* * *}$ & 0.05 & 7.45 & .0000 \\
\hline ASC & $2.52^{\star \star \star}$ & 0.11 & 23.01 & .0000 \\
\hline Log likelihood function & -8320.02 & & & \\
\hline McFadden Pseudo R-square & ed $\quad 0.23$ & & & \\
\hline
\end{tabular}

a) coefficients are for one of three stands being broadleaves or mixed instead of conifers 
b) coefficients are for one of three stands being of low, high height or uneven-aged respectively instead of newly established 
Table 3 presents the willingness-to-travel (WTT) estimates based on results from Table 3 with standard errors calculated using the Delta method (Greene, 2012b). At stand level, we see that presence of broadleaved and mixed tree species as opposed to conifers would positively influence respondent's WTT to a forest for recreation. They are willing to travel additional $3.62 \mathrm{~km}$ for having one broadleaved stand out of three and $4.98 \mathrm{~km}$ for mixed stand (in both cases instead of a coniferous stand). Thus, we cannot reject the $3^{\text {rd }}$ hypothesis that mixed stands are preferred over pure broadleaves or conifers. Among stands where trees are of the same height, stands with higher trees are preferred over those with lower trees. People are willing to travel additional 10.38 $\mathrm{km}$ and $11.85 \mathrm{~km}$ for seeing one stand out of three consisting of low or high trees respectively compared to newly established trees. Also, stands with trees of varying heights are favoured over stands with trees of same height, where people are willing to travel additional $14.35 \mathrm{~km}$ to experience one stand composed of trees of varying height compared to a newly established stand. Thus, we cannot reject the $4^{\text {th }}$ hypothesis that stands with trees of varying height are preferred over those with trees of the same height. In conclusion, on a stand level respondents prefer more diverse stands both in terms of tree species composition and height structure. 
Table 3: Estimated mean WTT and WTP across all respondents ${ }^{a}$

\begin{tabular}{|c|c|c|c|c|}
\hline Attributes & WTT, km & $\begin{array}{c}\text { Standard } \\
\text { error }\end{array}$ & $\begin{array}{c}\text { 95\% Confidence } \\
\text { interval }\end{array}$ & $\begin{array}{l}\text { WTP }^{b} \\
\text { DKK }\end{array}$ \\
\hline Broadleaves & $3.62^{* \star *}$ & 0.27 & $3.10-4.15$ & 14.48 \\
\hline Mixed & $4.98^{* \star *}$ & 0.30 & $4.39-5.57$ & 19.92 \\
\hline Low trees & $10.38^{* * *}$ & 0.34 & $9.72-11.05$ & 41.52 \\
\hline High trees & $11.85^{\star \star *}$ & 0.35 & $11.16-12.53$ & 47.40 \\
\hline Trees of varying height & $14.35^{\star * *}$ & 0.41 & $13.55-15.16$ & 57.40 \\
\hline $\begin{array}{l}\text { Tree species diversity across } \\
\text { stands }\end{array}$ & $2.27^{\star \star *}$ & 0.30 & $1.68-2.85$ & 9.08 \\
\hline $\begin{array}{l}\text { Tree height diversity across } \\
\text { stands }\end{array}$ & $2.30^{* * *}$ & 0.32 & $1.67-2.94$ & 9.20 \\
\hline \multicolumn{5}{|c|}{$\begin{array}{l}\text { Note: } \\
\text { a) The WTT for ASC is }-13.5 \mathrm{~km} \text {. Analytically this equals visiting a newly established coniferous }\end{array}$} \\
\hline
\end{tabular}


Variation in tree species and in height between stands positively affects the recreational attractiveness of the forest. People are willing to travel $2.27 \mathrm{~km}$ extra to reach a forest in which only two out of three stands are of the same tree species composition relative to of all of them being of the same species. Similarly, they are willing to travel $2.30 \mathrm{~km}$ extra to visit a forest in which two out of three stands have the same height instead of all of them having the same height. Thus, we cannot reject the first two hypotheses.

The next question is if diversity between stands can outweigh diversity within a stand. As it is evident from Table 3, this depends on the exact composition of the forest, which in this case is limited to tree species composition and height of each stand. With levels of these attributes established for this study (Table 1) and forest assumed to be comprised of three stands, there are 364 possible forest combinations (where the order of forest types does not matter). We calculate the aggregated willingness to travel (AWTT) for each of these possible forests using the following formula:

$A W T T=A S C+\sum W T T_{i} * N_{i}$

Where: $i=$ attributes (WTT for each attribute), and $N$ is the level of attribute (see Table 1 column 2).

First we calculate AWTT using sample mean WTT from Table 3. For example, applying the above equation to a forest consisting of two stands of mixed tree species of varying height and one high broadleaved stand (Figure $2 \mathrm{~b}$ ) results in following:

$\mathrm{AWTT}=\mathrm{ASC}+1{ }^{*} \mathrm{WTT}_{\text {broadleaves }}+2{ }^{*} \mathrm{WTT}_{\text {mixed }}+1{ }^{*} \mathrm{WTT}_{\text {high_trees }}+2^{*} \mathrm{WTT}_{\text {trees_of_varying_height }}+$ $1 * \mathrm{WTT}_{\text {tree_species_diversity_across_stands }}+1{ }^{*} \mathrm{WTT}_{\text {tree_height_diversity_across_stands }}=45.2 \mathrm{~km}$.

Forest consisting of three stands with tree species of varying height (Figure 2a) has slightly lower AWTT $(44,5 \mathrm{~km})$, but the difference is not significant. A forest with 
maximum species diversity across stands but no height variation has a little lower AWTT of $35.2 \mathrm{~km}$ (Figure 2c), whereas a forest with maximum height diversity and no species diversity is a lot lower $(24.2 \mathrm{~km}$, Figure $2 \mathrm{~d})$. Figure A in the supplementary materials shows the distribution of AWTT for all 364 combinations for a sample mean WTT, and as is seen a number of them lie relatively close.
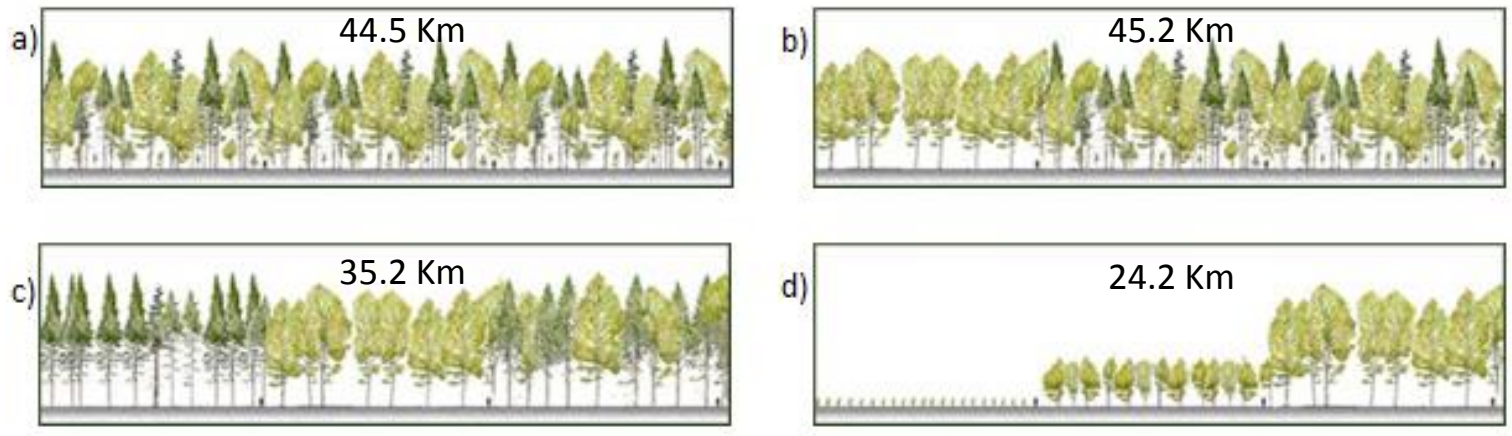

Figure 2: Examples of forests representing different combinations of tree species, stand height, tree species diversity, and height diversity. Note that each forest is assumed to be comprised of three stands.

To analyse heterogeneity in this respect, we also calculate every respondent's AWTT for each of the 364 possible forests combinations of three drawings using the posterior individual coefficients from the RPL estimation and AWTT equation. Only $14 \%$ of respondents chose a combination consisting entirely of stands of trees of mixed species and varying height (Fig. 2a). Thus, diversity across stands matter, and may outweigh diversity within a stand. In most cases however, presence of high trees or trees of varying height with species variation between or within stands results in an AWTT in the high end.

As a consistency check of findings from the choice experiment, we use the result of people's constructed ideal forest. As shown in Table 4 around $50 \%$ of the respondents composed a forest, which consists of drawings that represent either two types of tree 
species or two types of height structures. $95 \%$ of the respondents composed an ideal forest with an estimated AWTT, which lies within a $95 \%$ confidence interval of the AWTT for the most preferred forest estimated based on the posterior beta parameters from the CE. Thus, the construction of ideal forest supports the findings of the choice experiment that variation between stands matter. 
Table 4: Results from creating the ideal forest exercise: percentage of respondents considering levels of diversity in tree species composition and height in three stands they chose

\begin{tabular}{lcc}
\hline Level of diversity across three stands & \multicolumn{2}{c}{ Attribute } \\
\cline { 2 - 3 } & Tree species & Tree height, \% \\
& composition, \% \\
\hline "0" - All three stands share the same & 19.5 & 33.3 \\
level of the attribute & & 51.9 \\
"1" - 2 stands have different levels & 48.1 & 14.8 \\
"2" - All 3 stands have different levels & 32.4 & 100.0 \\
\end{tabular}




\section{Discussion}

This study aims at evaluating the effect of variation in two forest characteristics (tree species composition and tree height structure) both within a stand and between stands on recreational value of a forest. Different levels of these two forest characteristics define the management (silvicultural system) that is being applied. Thus, the main motivation is to contribute to the understanding of how forests can be managed in order to better accommodate societal recreational preferences. We found that, within a given stand, mixed tree species are preferred to broadleaved and broadleaved are preferred to coniferous. In general, stands comprised of higher trees are preferred to those consisting of lower ones and stands of trees of varying height are preferred to stands of tree with same height. This is consistent with findings of previous studies (e.g. Ribe 1989; Nielsen et al. 2007b; Gundersen \& Frivold 2008; Giergiczny et al. 2015).

If these findings were to be extrapolated from stand level to forest level without any additional considerations, the preferred forest would be comprised entirely of similar stands of uneven-aged mixed tree species. The question is whether a forest like this would have the highest recreational value? In order to analyse the effect of variation between stands on recreational value of a forest; our study's choice experiment specification also contained two diversity indices (tree species composition and height) that reflect variation between three stands. We find that both diversity in tree species and height structure between stands are positively contributing to individuals' choice of a forest to recreate in. The estimates for both diversity measures across stands are approximately of the same magnitude. For tree species composition, the magnitude of diversity between stands is compatible with the difference between two levels of variation within stand (broadleaved monocultures and mixed tree species) which indicates that in some instances monocultures could be preferred over mixed stands. We see that a forest comprised of three similar stands of mixed tree species gives a 
slightly lower AWTT than one consisting of two stands of mixed tree species and one broadleaved monoculture stand. Regarding height (age), the diversity across stands is not enough to outweigh the difference in AWTT within a stand. However, considering the uncertainty in the estimates, the differences are not significant, leading us to conclude that variation between stands with regard to both height and species, can outweigh lack of variation within a stand and vice versa.

This study assumes that variation between stands contributes linearly to utility. However, Axelsson-Lindgren (1995), Ode \& Miller (2011) and Edwards et al. (2012a) find that too much or too little diversity may have a negative effect on the recreational value of forests. To allow for a different functional form two additional models were estimated: a) with a log specification of the diversity indices which can reflect diminishing marginal utility and b) a specification with dummy coding of diversity. In doing so, only minor improvements have been reached in terms of the log-likelihood function (by four units in log specification and seven units in dummy specification) from the original linear specification; and it does not lead to different conclusions. Consequently, assuming linearity seems reasonable.

In this study we showed respondents three stands beside each other. It is possible that the absolute positioning (left, middle, right) as well as the relative one (what is next to a given stand) matters for the variation measures. While we find no significant difference between attributes allowing them to vary between absolute positioning, we do find that relative positioning may have an effect ${ }^{89}$. However, this was not included in the design of the survey, and as we are talking about third-order interactions, without explicit

\footnotetext{
${ }^{8}$ We tested it by creating a dummy for whether the stand next to a given one was identical or not, and then interacting this with the diversity measures.

${ }^{9}$ These two extra models can be obtained from authors upon request.
} 
consideration in the design, results may be biased. To what degree respondents took specific positioning into account is unknown - we only know for certain that they were asked to consider each stand as a representation of proportion of a forest. In order to fully answer this issue, we would need other ways to present the forest structural data, e.g. based on video visualizations or actual habits.

Basing the study on drawings involves a level of abstraction, which is higher than if photos were used. However, it makes the illustrations less sensitive to light conditions and positioning of individual trees and easier to control different aspects of the content and thus was considered as more suitable for this study. Yet, other options exist, which may improve respondents' ability to better capture the reality. One such option is to invite respondents into an actual forest and let them chose their most preferred recreational paths. Also, findings could be checked by performing comparison with actual recreational habits of respondents. We leave such possible extensions to future research.

An obvious question is to what degree these findings can be transferred to other countries. Looking at the results from Edwards et al (2012a) comparing preferences for forest structure for recreation by a Delphi study, tree size and species variation are some of the important attributes in most countries investigated. This speaks for results being transferable. The study is carried out in Denmark; a country where forestry has been dominated by even-aged monocultures. Consequently, it is likely that this anchoring would make the preference for variation between stands more pronounced. But to what degree remains an open question.

In this study we focused on recreational values of variation. However, people may have other values associated with variation in height or species - namely a non-use value in the form of e.g. naturalness (see e.g. Czajkowski et al. (2009), Campbell et al. (2014)). 
It is unlikely that they are distinguishable from recreational values per se, but by focusing on transport distance as in this study we are likely to have higher emphasis on only the recreational values than in e.g. Nielsen et al. (2007) or the above mentioned studies using a monetary payment vehicle.

Findings of this study contribute to the on-going debate regarding the choice between even-aged or uneven-aged forest management and add to the question of striking a desired balance between public goods and production of timber. On one hand, stands of uneven-aged mixed tree species provides the highest variation within a stand and is on average the most preferred option at that level, supporting the argument for closeto-nature management or at least application of selection silvicultural systems. On the other hand, variation between stands also positively contributes to recreational value of forest. One could suppose that if close-to-nature forestry is implemented everywhere, it might reduce the variation on a forest level and result in loss of a portion of the recreational value. Even though results of the current study do not support a hypothesis that a mix of stands in different ages of clear-cut forestry is preferred on a between stands level, presence of least favoured stands is unavoidable and could be beneficial for recreation due to inter-stands variation. Also, trees in mature age in evenaged forest management are associated with relatively high recreational value. Thus, for management it suggested to promote both types of variation (within and between stands) through a variety of forest characteristics and management regimes. Finally, since variation is important for the recreational experience, the management should also allow the visitor to experience other types of variation, e.g. visual transparency allowing the visitor to observe geological and topographical variation. 


\section{Acknowledgements}

We thank Anders Busse Nielsen for allowing the use of the drawings. Furthermore, the authors affiliated with Centre for Macroecology, Evolution and Climate acknowledge funding from the Danish National Research Foundation (grant number DNRF96). Anna Filyushkina and Fitalew Agimass Taye were funded by the Education, Audiovisual and Culture Executive Agency (EACEA) of the European Commission under Erasmus Mundus Action 1 through individual Doctoral fellowships as part of the Erasmus Mundus Joint Doctoral Program "Forests and Nature for Society" (FONASO).

\section{References}

Abildtrup, J., Garcia, S., Olsen, S.B., Stenger, A., 2013. Spatial preference heterogeneity in forest recreation. Ecol. Econ. 92, 67-77. doi:10.1016/j.ecolecon.2013.01.001

Adamowicz, W., Boxall, P., Williams, M., Louviere, J., 1998. Stated preference approaches for measuring passive use values: Choice experiments and contingent valuation. Am. J. Agric. Econ. 80, 64-75. doi:10.2307/3180269

Axelsson-Lindgren, C., 1995. Forest aesthetics, in: Multiple-Use Forestry in the Nordic Countries. Metla, Finnish Forest Research Institute, Helsinki Research Centre, Jyväskylä, pp. 279-293.

Axelsson-Lindgren, C., Sorte, G., 1987. Public response to differences between visually distinguishable forest stands in a recreation area. Landsc. Urban Plan. 14, 211-217. doi:10.1016/0169-2046(87)90030-2

Bakhtiari, F., Jacobsen, J.B., Jensen, F.S., 2014. Willingness to travel to avoid recreation conflicts in Danish forests. Urban For. Urban Green. 13, 662-671. 
Bell, S., 2009. Valuable Broadleaved Trees in the Landscape, in: Spiecker, H., Hein, S., Makkonen-Spiecker, K., Thies, M. (Eds.), Valuable Broadleaved Forests in Europe. Brill Academic Publishers, Boston, MA, pp. 171-200.

Bell, S., Blom, D., Rautamäki, M., Simson, A., Asger, I., 2005. Design of Urban Forests, in: Urban Forests and Trees. Springer-Verlag, pp. 149-186.

Bliss, J., 2000. Public perceptions of clearcutting. J. For. 4-9.

Brown, T.C., Daniel, T.C., 1986. Predicting scenic beauty of timber stands. For. Sci. 32, 471-487.

Campbell, D., Vedel, S.E., Thorsen, B.J., Jacobsen, J.B., 2014. Heterogeneity in the WTP for recreational access: distributional aspects. J. Environ. Plan. Manag. 57, 1200-1219. doi:10.1080/09640568.2013.793173

Carlsson, F., Frykblom, P., Liljenstolpe, C., 2003. Valuing wetland attributes: An application of choice experiments. Ecol. Econ. 47, 95-103. doi:10.1016/j.ecolecon.2002.09.003

Czajkowski, M., Buszko-Briggs, M., Hanley, N., 2009. Valuing changes in forest biodiversity. Ecol. Econ. 68, 2910-2917.

Daniel, T.C., Muhar, A., Arnberger, A., Aznar, O., Boyd, J.W., Chan, K.M. a, Costanza, R., Elmqvist, T., Flint, C.G., Gobster, P.H., Grêt-Regamey, A., Lave, R., Muhar, S., Penker, M., Ribe, R.G., Schauppenlehner, T., Sikor, T., Soloviy, I., Spierenburg, M., Taczanowska, K., Tam, J., von der Dunk, A., 2012. Contributions of cultural services to the ecosystem services agenda. Proc. Natl. Acad. Sci. U. S. A. $109,8812-9$. doi:10.1073/pnas.1114773109

Dhakal, B., Yao, R.T., Turner, J. a., Barnard, T., 2012. Recreational users' willingness to pay and preferences for changes in planted forest features. For. Policy Econ. 17, 34-44. doi:10.1016/j.forpol.2011.11.006 
Edwards, D., Jay, M., Jensen, F.S., Lucas, B., Marzano, M., Montagné, C., Peace, A., Weiss, G., 2012a. Public preferences for structural attributes of forests: Towards a pan-European perspective. For. Policy Econ. 19, 12-19.

doi:10.1016/j.forpol.2011.07.006

Edwards, D., Jay, M., Jensen, F.S., Lucas, B., Marzano, M., Montagné, C., Peace, A., Weiss, G., 2012b. Public preferences across europe for different forest stand types as sites for recreation. Ecol. Soc. 17, 27. doi:10.5751/ES-04520-170126

Elsasser, P., Englert, H., Hamilton, J., 2010. Landscape benefits of a forest conversion pro- gramme in North East Germany: results of a choice experiment. Ann. For. Res. 53, 37-50.

Federation of Danish Motorists in Denmark (FDM) [WWW Document], n.d. . 2009. URL http://jyllands-posten.dk/livsstil/biler/ECE4083757/din-bil-koster-dig-3-76-kr-perkilometer/ (accessed 9.9.15).

Giergiczny, M., Czajkowski, M., Żylicz, T., Angelstam, P., 2015. Choice experiment assessment of public preferences for forest structural attributes. Ecol. Econ. 119, 8-23. doi:10.1016/j.ecolecon.2015.07.032

Greene, W.H., 2012a. NLOGIT, Version 5. New York.

Greene, W.H., 2012b. Econometric analysis. Pearson Education Limited, Essex.

Gundersen, V.S., Frivold, L.H., 2008. Public preferences for forest structures: A review of quantitative surveys from Finland, Norway and Sweden. Urban For. Urban Green. 7, 241-258. doi:10.1016/j.ufug.2008.05.001

Gustavsson, R., Hermy, M., Konijnendijk, C., Steidle-Schwahn, A., 2005. Management of urban woodland and parks-searching for creative and sustainable concepts, in: Urban Forests and Trees. Springer, Berllin Heidelberg, pp. 369-397. doi:10.1007/3-540-27684-X_14 
Haakenstad, H., 1972. Forest management in an area of outdoor life. An investigation of public opinion about Oslomarka. Survey A and Survey B. Meldinger fra Norges Landbrukshøgskole No. 16 (In Norwegian with English summary). As.

Hanley, N., Wright, R.E., Adamowicz, V.I.C., 1998. Using Choice Experiments to Value the Environment 11, 413-428.

Hanley, N., Wright, R.E., Koop, G., 2002. Modelling recreational demand using choice experiments: climbing in Scotland. Environ. Resour. Econ. 22, 449-466.

Heyman, E., 2012. Analysing recreational values and management effects in an urban forest with the visitor-employed photography method. Urban For. Urban Green. 11, 267-277. doi:10.1016/j.ufug.2012.02.003

Heyman, E., Gunnarsson, B., Stenseke, M., Henningsson, S., Tim, G., 2011. Openness as a key-variable for analysis of management trade-offs in urban woodlands. Urban For. Urban Green. 10, 281-293. doi:10.1016/j.ufug.2011.07.003

Holgén, P., Mattsson, L., Li, C.-Z., 2000. Recreation values of boreal forest stand types and landscapes resulting from different silvicultural systems: An economic analysis. J. Environ. Manage. 60, 173-180. doi:10.1006/jema.2000.0377

Jensen, F.S., 2003. Friluftsliv I 592 skove og andre naturområdet. Skovbrugsserien. nr 32. Hørsholm.

Jensen, F.S., 1999a. Forest recreation in Denmark from the 1970s to the 1990s. Hørsholm.

Jensen, F.S., 1999b. Changes in the forest preferences of the Danish population from 1977 to 1994 , Forest recreation in Denmark from 1970 to the 1990 s. The research series. Hørsholm. 
Kaplan, R., Kaplan, S., 1989. The experience of nature. Cambridge University Press, Cambridge.

Koch, N.E., Jensen, F.S., 1988. Skovenes friluftsfunktion i Danmark. IV. del. Befolkningens ønsker til skovenes og det åbne lands udformning (Forest Recreation in Denmark. Part IV: The Preferences of the Population). Hørsholm.

Lancaster, K.J., 1966. A new approach to consumer theory. J. Polit. Econ. 74, 132157.

Lee, T., 2001. Perceptions, Attitudes and Preferences in Forests and Woodlands. Edinburgh.

Lindgren, 1995. Forest aesthetics, in: Hytönen, M. (Ed.), Multiple-Use Forestry in the Nordic Countries. Metla, Finnish Forest Research Institute, Helsinki Research Centre, Jyväskylä, pp. 279-293.

Lindhagen, A., Hörnsten, L., 2000. Forest recreation in 1977 and 1997 in Sweden: changes in public preferences and behaviour. Forestry 73, 143-153. doi:10.1093/forestry/73.2.143

Louviere, J.J., Hensher, D. a., Swait, J.D., 2000. Stated choice methods: analysis and application. Cambridge University Press, Cambridge. doi:10.1002/jae.701

Mattsson, L., Li, C., 1994. How do different forest management practices affect the non-timber value of forests?-an economic analysis. J. Environ. Manage. 41, 7988.

McFadden, D., 1973. Conditional logit analysis of qualitative choice behavior, in: P, Z. (Ed.), Frontiers in Econometrics. Academic Press Inc., New York, pp. 105-142.

Nielsen, A.B., Heyman, E., Richnau, G., 2012. Liked, disliked and unseen forest attributes: relation to modes of viewing and cognitive constructs. J. Environ. 
Manage. 113, 456-66. doi:10.1016/j.jenvman.2012.10.014

Nielsen, A.B., Jensen, R.B., 2007. Some visual aspects of planting design and silviculture across contemporary forest management paradigms - Perspectives for urban afforestation. Urban For. Urban Green. 6, 143-158. doi:10.1016/j.ufug.2006.12.002

Nielsen, A.B., Olsen, S.B., Lundhede, T., 2007. An economic valuation of the recreational benefits associated with nature-based forest management practices. Landsc. Urban Plan. 80, 63-71. doi:10.1016/j.landurbplan.2006.06.003

Ode, Å., Miller, D., 2011. Analysing the relationship between indicators of landscape complexity and preference. Environ. Plan. B Plan. Des. 38, 24-38. doi:10.1068/b35084

Ode, Å.K., Fry, G.L. a., 2002. Visual aspects in urban woodland management. Urban For. Urban Green. 1, 15-24. doi:10.1078/1618-8667-00003

Pearce, D.W., 2001. The economic value of forest ecosystems. Ecosyst. Heal. 7, 284296. doi:10.1046/j.1526-0992.2001.01037.x

Price, C., 2007. Landscape Preferences and Continuous Cover Forestry, The Robinwood Altman report: Landcape Preferences and Continuous Cover Forestry. Bangor.

Ribe, R.G., 1989. The aesthetics of forestry: What has empirical preference research taught us? Environ. Manage. 13, 55-74.

Scarpa, R., Chilton, S.M., Hutchinson, W.G.G., Buongiorno, J., 2000. Valuing the recreational benefits from the creation of nature reserves in Irish forests. Ecol. Econ. 33, 237-250. doi:10.1016/S0921-8009(99)00143-3

Schroeder, H., Daniel, T., 1981. Progress in predicting the perceived scenic beauty of 
forest landscapes. For. Sci. 27, 71-80.

Silvennoinen, H., Alho, J., Kolehmainen, O., Pukkala, T., 2001. Prediction models of landscape preferences at the forest stand level. Landsc. Urban Plan. 56, 11-20. doi:10.1016/S0169-2046(01)00163-3

Slee, B., 2005. Socio-economic values of natural forests. For. Snow Landsc. Res 79, $157-167$.

Tahvanainen, L., Tyrväinen, L., 2001. Forest management and public perceptions-visual versus verbal information. Landsc. Urban Plan. 53, 53-70.

Termansen, M., McClean, C.J., Jensen, F.S., 2013. Modelling and mapping spatial heterogeneity in forest recreation services. Ecol. Econ. 92, 48-57. doi:10.1016/j.ecolecon.2013.05.001

Train, K., 2003. Discrete Choice Methods with Simulation. Cambridge Univ. Press 1388. doi:10.1017/CBO9780511753930

Train, K.E., 1998. Recreation Demand Models with Taste Differences over People. Land Econ. 74, 230-239. doi:10.1212/WNL.0b013e3181dba0e6

Tyrväinen, L., Silvennoinen, H., Kolehmainen, O., 2003. Ecological and aesthetic values in urban forest management. Urban For. Urban Green. 1, 135-149.

Varela, E., Jacobsen, J.B., Mavsar, R., 2015. Social demand for ecosystem services provided by Mediterranean forests: A choice experiment application to Aleppo pine forests in Catalonia (in prep).

Willis, K.G., Garrod, G., Scarpa, R., Powe, N., Lovett, A., Bateman, I.J., Hanley, N., Macmillan, D.C., 2003. The Social and Environmental Benefits of Forests in Great Britain. Report to Forestry Commission Edinburgh. Newcastle.

Zube, E.H., Sell, J.L., Taylor, J.G., 1982. Landscape perception: Research, application 
and theory. Landsc. Plan. 9, 1-33. doi:10.1016/0304-3924(82)90009-0 